\title{
Modelling of Partial Discharge Behaviour in a Spherical Cavity within a Solid Dielectric Material as a Function of Temperature
}

\author{
H. A. Illias, G. Chen and P. L. Lewin \\ School of Electronics and Computer Science \\ University of Southampton, United Kingdom \\ Email: hai07r@ecs.soton.ac.uk
}

\begin{abstract}
Partial discharge (PD) is an electrical discharge within a dielectric which does not bridge the electrodes. PD measurement has been widely used for assessing performance of insulation systems. Modelling of PD activity gives an insight of this activity and can provide important information for insulation diagnosis. In this paper, a finite element analysis (FEA) method has been used to build a model of PD activity within a spherical cavity in a dielectric material. The model has been used to study critical parameters and physical mechanisms affecting PD activity as a function of temperature. Critical parameters from the model have been identified through comparison between simulation and measurement results.
\end{abstract}

\section{INTRODUCTION}

Partial discharge (PD) measurement is an important indicator for insulation system health and fault diagnosis. Insulation is more prone to PD when there are defects present that are stressed under a high electric field. Examples of defect that might exist in insulation system are cavities, joints, cracks or delaminations. PD at the defect site within insulation might cause degradation of the insulation system, leading to breakdown of the system under certain conditions depending on the quality of the insulation design and the location and type of the defect [1].

The conditions of the applied stress and defect conditions in the material can affect the occurrence of PD activity. One of the factors affecting PD patterns is the temperature of the material. In previous work, it has been found the number of PDs per cycle within a spherical cavity in an epoxy resin is lower but the maximum PD magnitude is larger at higher temperatures [2]. In this model, it has been assumed that the electron generation rate decreases with temperature because of the increased cavity surface work function. The electron generation rate is also reduced because the inception field is higher due to the increased initial pressure in the cavity at higher temperatures.

Since the temperature of dielectric materials can vary depending on operational conditions, it is reasonable to study PD activity within a defect in a dielectric material at different ambient temperatures. In this paper, a FEA model has been developed to study PD activity in a spherical cavity for different temperatures of the material. The simulation data are compared with the measurement results to evaluate critical parameters affecting PD activity. The temperature changed caused by PD on the subsequence of PD events is studied as well.

\section{EXPERIMENTAL SETUP}

The IEC60270 experiment for measurement of PD activity is shown in Fig. 1. The experiment consists of a high voltage supply, V, a coupling capacitor, $\mathrm{C}_{\mathrm{k}}$, a test object, a coupling device, a PD detector and a USB controller, which is connected to a personal computer (PC). The coupling device and the PD detector detect the PD signals from the test object. The output is then sent to the PC for data processing.

Fig. 2 shows the schematic diagram of the test object. The test object is made of epoxy resin of $2.5 \mathrm{~mm}$ thickness. A spherical cavity of $1.7 \mathrm{~mm}$ diameter in a smaller epoxy resin block of $2 \mathrm{~mm}$ thickness is placed in the middle of the larger epoxy resin block. A spherical cavity was prepared by injecting a bubble in the resin before it is left for cure for 24 hours at room temperature, post cure for 4 hours at $90^{\circ} \mathrm{C}$ and finally cooling at room temperature. The whole test object was immersed in mineral oil to prevent surface discharges around the edge of the electrode. A $50 \mathrm{~Hz}, 20 \mathrm{kV}$ ac sinusoidal voltage was applied to the test object and the temperature of the material was set at $20,35,50$ and $65^{\circ} \mathrm{C}$.

\section{MODELLING OF PD}

Fig. 3 details the two-dimensional (2D) axial-symmetric model geometry of the test object. It consists of a homogenous dielectric material of $2.5 \mathrm{~mm}$ thickness and $10 \mathrm{~mm}$ diameter, a hemispherical cavity of $1.7 \mathrm{~mm}$ diameter due to the centre axis of symmetry and a cavity surface of $0.05 \mathrm{~mm}$ thickness to model the surface charge decay through conduction along the

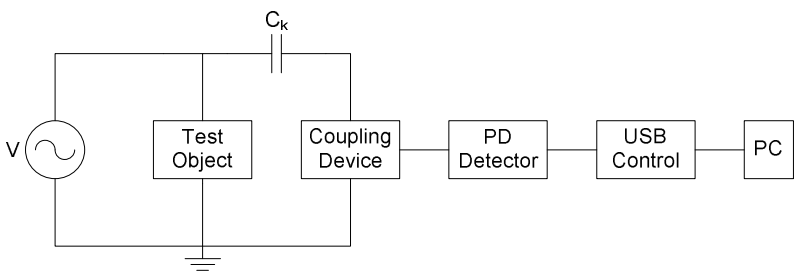

Fig. 1. Schematic diagram of the experimental setup 


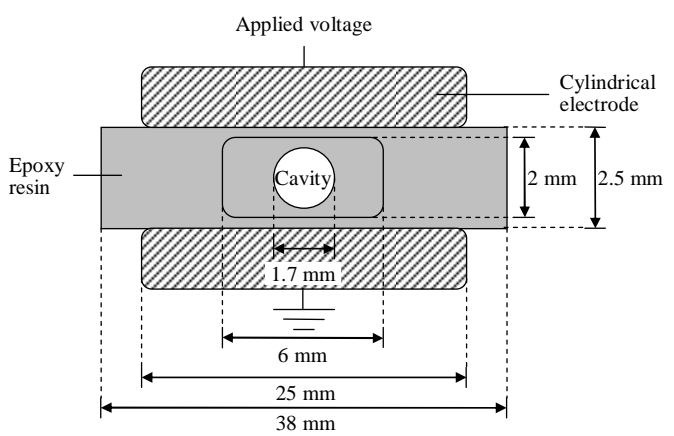

Fig. 2. Schematic diagram of the test object

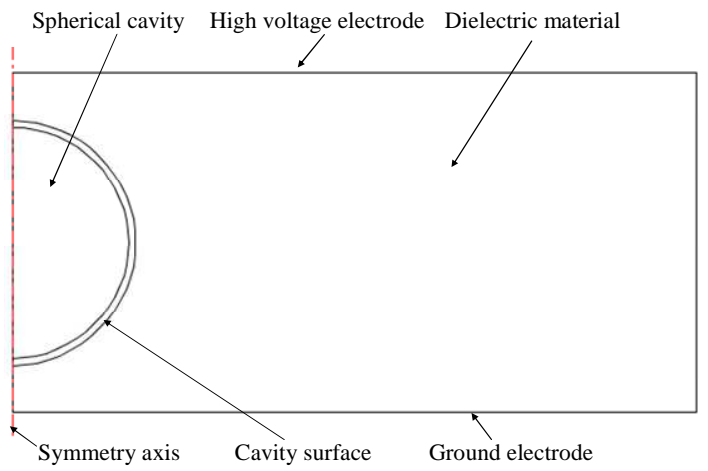

Fig. 3. 2D axial-symmetric model geometry

cavity wall. A $50 \mathrm{~Hz}, 20 \mathrm{kV}$ ac sinusoidal voltage was applied to the upper electrode while the lower electrode was grounded. The temperature of the material is varied from 20 to $65^{\circ} \mathrm{C}$.

The temperature distribution in the model is solved by a heat transfer module using

$$
\rho \mathrm{C}_{\mathrm{p}} \partial \mathrm{T} / \partial \mathrm{t}-\nabla \bullet(\mathrm{k} \nabla \mathrm{T})=\mathrm{Q}
$$

where $C_{p}$ is the specific heat capacity, $k$ is the thermal conductivity, $\mathrm{T}$ is the temperature, $\rho$ is the mass density, and $\mathrm{Q}$ is the heat source density. $\mathrm{Q}$ is calculated using

$$
\mathrm{Q}=\left(\varepsilon / 2 \int\left(\mathrm{E}_{\mathrm{PD}}{ }^{2}-\mathrm{E}_{\mathrm{ext}}{ }^{2}\right) \mathrm{dv}\right) /\left(\mathrm{t}_{\mathrm{PD}} \mathrm{v}\right)
$$

where the numerator is the energy dissipated due to $\mathrm{PD}, \varepsilon$ is the permittivity, $E_{P D}$ is the initial field of $P D$ event, $E_{\text {ext }}$ is the extinction filed, $t_{P D}$ is PD time interval and $\mathrm{v}$ is the cavity volume. The electric field distribution is solved using

$$
\varepsilon \nabla(\partial \mathrm{V} / \partial \mathrm{t})+\sigma \nabla \mathrm{V}=0
$$

where $\sigma$ is the conductivity, and $\mathrm{V}$ is the electric potential.

Fig. 4 shows the flowchart of the program to interface with the FEA model. Initially, the boundary and subdomain of the model are initialized. At each time step, the values of voltage across the cavity, $\mathrm{U}_{\text {cav }}$, inception voltage, $\mathrm{U}_{\text {inc }}$, voltage due to cavity surface charge, $U_{s}$ and temperature in the cavity, $T_{\text {cav }}$ are recalculated.
In order to consider surface charge decay through conduction along the cavity wall, the polarity of $U_{\text {cav }}$ and $U_{\mathrm{s}}$ is compared. If both have the opposite polarity of each other, surface conductivity, $\sigma_{\mathrm{s}}$ is set to initial value, $\sigma_{\mathrm{s} 0}$. If their polarities are the same, $\sigma_{\mathrm{s}}$ is increased and calculated using

$$
\sigma_{\mathrm{s}}=\sigma_{\mathrm{s} 0} \exp \left|\mathrm{U}_{\text {cav }} / \mathrm{U}_{\text {decay }}+\mathrm{T}_{\mathrm{s}} / \mathrm{T}_{\text {room }}\right|
$$

where $\mathrm{U}_{\text {decay }}$ is the voltage across the cavity that causes surface charge to decay, $T_{s}$ is the temperature on the cavity surface and $T_{\text {room }}$ is room temperature $(293 \mathrm{~K})$ [3]. The cavity surface conductivity is limited by a maximum conductivity value, $\sigma_{\text {smax }}$ to avoid numerical convergence problems. Then, $U_{\text {cav }}$ is checked whether it exceeds $U_{\text {inc }}$ or not. If $U_{\text {cav }}>U_{\text {inc }}$, the total electron generation rate, $\mathrm{N}_{\mathrm{et}}$ is calculated using

$$
\mathrm{N}_{\text {et }}=\left(\mathrm{N}_{\text {ed }}+\mathrm{N}_{\text {ei }}\right) \exp \left|\mathrm{U}_{\text {cav }} / \mathrm{U}_{\text {inc }} \cdot \mathrm{T}_{\text {mat }} / \mathrm{T}_{\text {room }}\right|
$$

where $\mathrm{N}_{\mathrm{ed}}$ and $\mathrm{N}_{\mathrm{ei}}$ are the electron generation rate (EGR) due to charge detrapping from the shallow traps and from loose polymer chain ends respectively and $\mathrm{T}_{\mathrm{mat}}$ is the material temperature. $\mathrm{N}_{\mathrm{ed}}$ is calculated using

$$
\mathrm{N}_{\mathrm{ed}}=\mathrm{N}_{\mathrm{ed} 0}\left|\mathrm{U}_{\mathrm{PD}} / \mathrm{U}_{\mathrm{inc}}\right| \exp \left(-\mathrm{t} / \tau_{\text {trap }}\right)
$$

where $\mathrm{N}_{\mathrm{ed} 0}$ is the initial electron generation rate due to charge detrapping from the shallow traps, $\mathrm{U}_{\mathrm{PD}}$ is the cavity voltage of previous PD event, $t$ is the time elapsed since previous PD event and $\tau_{\text {trap }}$ is the effective lifetime of detrappable electron. $\mathrm{N}_{\text {ed0 }}$ is subdivided into two values, $\mathrm{N}_{\text {edoL }}$ which is used when $\mathrm{U}_{\text {cav }}$ and $\mathrm{U}_{\mathrm{s}}$ have the same polarity and $\mathrm{N}_{\mathrm{edOH}}$ when $\mathrm{U}_{\mathrm{cav}}$ and $\mathrm{U}_{\mathrm{s}}$ have the opposite polarity [3].

The probability, $\mathrm{P}$, of a PD to occur in the time interval, $\mathrm{dt}$ is calculated using [3]

$$
\mathrm{P}=1-\exp \left(-\mathrm{N}_{\mathrm{et}} \mathrm{dt}\right)
$$

$\mathrm{P}$ is compared with a random number $\mathrm{R}(0<\mathrm{R}<1)$. A discharge will occur only if $\mathrm{P}$ is greater than $\mathrm{R}$. Discharge is modelled by increasing the initial cavity conductivity, $\sigma_{\text {cav } 0}$ to maximum conductivity, $\sigma_{\text {cavmax }}$. Discharge stops when $\mathrm{U}_{\text {cav }}$ becomes less than the extinction voltage, $\mathrm{U}_{\text {ext }}$. PD real and apparent charge magnitude is calculated by time integration of current through the maximum cross sectional area of the cavity and through the ground electrode during PD respectively.

After a PD event, the temperature in the cavity increases. In this model, the heat density is increased from zero during the PD interval, resulting in the temperature in the cavity increasing from its initial value. The increase in temperature causes the pressure in the cavity to also increase, resulting in a higher inception voltage [4-6].

\section{RESUlTS AND DisCUSSION}

The PD measurement and simulation results as a function of temperature are shown in Table 1 and Table 2. From Table 1, with increasing temperature, the number of PDs per cycle, the 


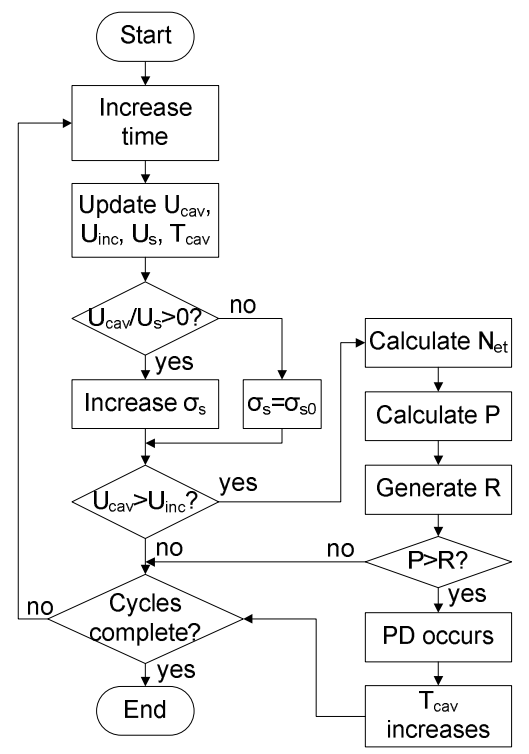

Fig. 4. Flowchart of the program

total charge per cycle and minimum charge magnitude increase but the maximum charge magnitude decreases. The temperature has no obvious effect on the mean charge magnitude. These results contradict with other published work, which reports the number of PDs per cycle to decrease at higher material temperatures because the cavity surface work function is higher, reducing electron generation rate, resulting in less number of PDs per cycle $[2,7]$. However, in this work, we believe that the PD repetition rate at higher temperature is due to a larger electron generation rate because electron surface emission is enhanced by higher material temperatures.

At higher temperatures, the maximum PD magnitude decreases due to the higher electron generation rate, which reduces any statistical time lags. Thus, PDs occur at lower voltages across the cavity, yielding a lower maximum PD magnitude. However, the minimum charge magnitude increases with temperature. The higher initial pressure in the cavity causes the inception voltage to become higher, resulting in a larger voltage drop across the cavity when the PD occurs after the inception voltage has been exceeded.

The $\varphi$-q-n plots of the measurement and simulation results as a function of temperature are shown in Fig 5. From Fig. $5(\mathrm{a}-\mathrm{d})$, at higher temperature, the density of PDs occurring near the minimum charge amplitude increases and the tail of the 'rabbit-ear' like pattern, by referring on the charge amplitude-phase axes stops at an earlier phase position. The reason for this may be explained as follows; electron generation rate is enhanced by the temperature increase of the material, causing more PDs to occur at earlier phase with lower charge magnitude. From Table 1, Table 2 and Fig. 5, the simulation results can be said to be within fairly reasonable agreement with measurement results although there are slight differences in some of the data and $\varphi$-q-n plots.

Table 3 shows the definition of parameters used for the simulation. The measured material permittivity increases with
TABLE I

MEAsurement Results For DifFERENT Temperatures

\begin{tabular}{|l|c|c|c|c|}
\hline \multicolumn{1}{|c|}{ Temperature $\left({ }^{\circ} \mathrm{C}\right)$} & 20 & 35 & 50 & 65 \\
\hline Total PDs per cycle & 6.5 & 8.5 & 10.6 & 12.4 \\
\hline Total charge per cycle (pC) & 3672 & 5163 & 5580 & 6913 \\
\hline Mean charge magnitude (pC) & 561 & 610 & 524 & 557 \\
\hline Maximum PD magnitude (pC) & 2257 & 1848 & 1189 & 1241 \\
\hline Minimum PD magnitude (pC) & 375 & 425 & 425 & 438 \\
\hline
\end{tabular}

TABLE II

SimUlation RESUltS FOR DIFFERENT TEMPERATURES

\begin{tabular}{|l|c|c|c|c|}
\hline \multicolumn{1}{|c|}{ Temperature $\left({ }^{\circ} \mathrm{C}\right)$} & 20 & 35 & 50 & 65 \\
\hline Total PDs per cycle & 6.5 & 8.5 & 10.5 & 12.3 \\
\hline Total charge per cycle (pC) & 4344 & 4603 & 4955 & 5782 \\
\hline Mean charge magnitude (pC) & 665 & 540 & 471 & 469 \\
\hline Maximum PD magnitude (pC) & 2355 & 1802 & 1174 & 1051 \\
\hline Minimum PD magnitude (pC) & 376 & 424 & 425 & 439 \\
\hline
\end{tabular}
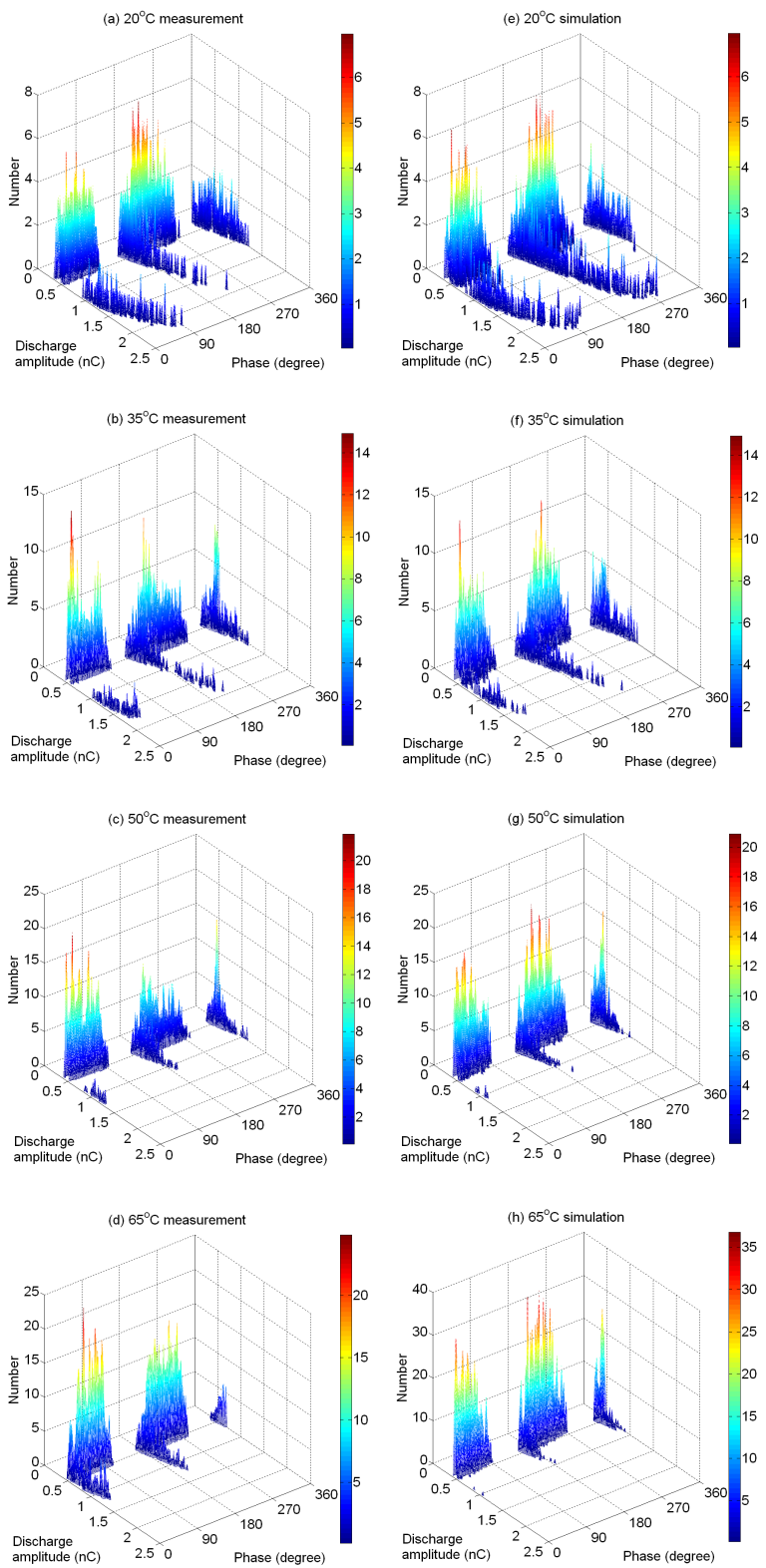

Fig. 5. $\varphi-\mathrm{q}-\mathrm{n}$ plots of measurement (a-d) and simulation (e-h) results 
temperature. From the simulation, the initial electron generation rate due to charge detrapping from shallow traps, $\mathrm{N}_{\mathrm{edOH}}$ and $\mathrm{N}_{\mathrm{edOL}}$ increases with temperature. This is because more electrons are available to initiate a PD in the cavity at higher temperature. $\mathrm{N}_{\mathrm{ei}}$ is assumed to be constant. The value for $\tau_{\text {trap }}$ is larger at higher temperature because electrons in shallow traps can be detrapped more easily. When the temperature is increased, the initial inception voltage, $\mathrm{U}_{\text {inc0 }}$ is higher because the initial pressure, $\mathrm{p}_{0}$ in the cavity is higher. Hence, the simulated $\mathrm{p}_{0}$ increases with temperature. The initial extinction voltage, $\mathrm{U}_{\mathrm{ext} 0}$ also increases with temperature. As the movement of surface charges along the cavity wall is temperature dependent, this will result in faster charge decay rates at higher temperatures, $\sigma_{\text {smax }}$ is higher when the temperature is increased. [8]. $\mathrm{N}_{\text {ed0H }}, \mathrm{N}_{\text {edoL }}, \tau_{\text {trap }}$ and $\sigma_{\text {smax }}$ can be represented as a function of temperature, as shown in Table 3.

Fig. 6 shows simulation of PD charge amplitude and temperature in the middle of the cavity against phase angle for temperature 20 and $65^{\circ} \mathrm{C}$ for the first 10 cycles of the applied voltage. Assuming the temperature in the cavity decays exponentially, the average temperature decay time constant, $\tau_{\text {Tdecay }}$, for $20^{\circ} \mathrm{C}$ is $4 \mathrm{~ms}$ while for $65^{\circ} \mathrm{C}$ is $3 \mathrm{~ms}$. Although the temperature in the cavity does not recover to its initial value between consecutive discharges at $65^{\circ} \mathrm{C}$, the temperature increment after each PD is small. This is because there are many PDs occur with lower charge magnitudes and less with higher charge magnitudes. Therefore, the temperature change on PD activity has more effect at lower temperatures because the number of PDs occurring with higher charge magnitudes is larger than at higher temperatures, where larger charge magnitude causes higher temperature increase in the cavity.

TABLE III

DEFinition OF PARAMETERS USED FOR THE SiMUlation

\begin{tabular}{|c|c|c|c|c|c|c|}
\hline Definition & Symbol & \multicolumn{4}{|c|}{ Value } & Unit \\
\hline Time step during no PD & $\overline{\mathrm{dt}}$ & \multicolumn{4}{|c|}{$1 / 720 f$} & $\mathrm{~S}$ \\
\hline Cavity relative permittivity & $\varepsilon_{\text {rcav }}$ & \multicolumn{4}{|c|}{1} & \\
\hline Material conductivity & $\sigma_{\text {mat }}$ & \multicolumn{4}{|c|}{$1 \times 10^{-18}$} & $\mathrm{~S} / \mathrm{m}$ \\
\hline $\begin{array}{l}\text { Initial cavity surface } \\
\text { conductivity during no PD }\end{array}$ & $\sigma_{\mathrm{s} 0}$ & \multicolumn{4}{|c|}{$1 \times 10^{-18}$} & $\mathrm{~S} / \mathrm{m}$ \\
\hline $\begin{array}{l}\text { Cavity conductivity when no } \\
\text { PD }\end{array}$ & $\sigma_{\text {cav0 }}$ & \multicolumn{4}{|c|}{0} & $\mathrm{~S} / \mathrm{m}$ \\
\hline $\begin{array}{l}\text { Maximum cavity conductivity } \\
\text { during PD }\end{array}$ & $\sigma_{\text {cavmax }}$ & \multicolumn{4}{|c|}{$1 \times 10^{-2}$} & $\mathrm{~S} / \mathrm{m}$ \\
\hline $\begin{array}{l}\text { Cavity voltage for charge } \\
\text { decay }\end{array}$ & $\mathrm{U}_{\text {decay }}$ & \multicolumn{4}{|c|}{100} & $\mathrm{~V}$ \\
\hline $\begin{array}{l}\text { EGR due to charge detrapping } \\
\text { from loose polymer chain ends }\end{array}$ & $\mathrm{N}_{\mathrm{ei}}$ & \multicolumn{4}{|c|}{2} & $1 / \mathrm{s}$ \\
\hline Material temperature & $\mathrm{T}_{\text {mat }}$ & 20 & 35 & 50 & 65 & ${ }^{\circ} \mathrm{C}$ \\
\hline $\begin{array}{l}\text { Material and cavity surface } \\
\text { relative permittivity }\end{array}$ & $\varepsilon_{\mathrm{r}}$ & 4.4 & 4.5 & 4.9 & 6.0 & \\
\hline Initial pressure in the cavity & $\mathrm{p}_{0}$ & 85 & 90 & 95 & 100 & $\mathrm{kPa}$ \\
\hline Initial cavity inception voltage & $\mathrm{U}_{\text {inc } 0}$ & 5.90 & 6.17 & 6.44 & 6.70 & $\mathrm{kV}$ \\
\hline Initial extinction voltage & $\mathrm{U}_{\mathrm{ext} 0}$ & 1.56 & 1.36 & 2.03 & 3.01 & $\mathrm{kV}$ \\
\hline $\begin{array}{l}\text { Detrappable electron effective } \\
\text { lifetime }\end{array}$ & $\tau_{\text {trap }}$ & \multicolumn{4}{|c|}{$0.04533 \mathrm{~T}-11.3$} & $\mathrm{~ms}$ \\
\hline $\begin{array}{l}\text { Initial EGR due to charge } \\
\text { detrapping from shallow traps }\end{array}$ & $\begin{array}{l}\mathrm{N}_{\text {edOH }} \\
\mathrm{N}_{\mathrm{edOL}}\end{array}$ & \multicolumn{4}{|c|}{$\begin{array}{c}2.778 \mathrm{~T}^{2}-1519 \mathrm{~T}+2.081 \times 10^{5} \\
0.6 \mathrm{~N}_{\mathrm{ed} 0 \mathrm{H}}\end{array}$} & $\begin{array}{l}1 / \mathrm{s} \\
1 / \mathrm{s} \\
\end{array}$ \\
\hline $\begin{array}{l}\text { Maximum surface } \\
\text { conductivity for charge decay }\end{array}$ & $\sigma_{\text {smax }}$ & \multicolumn{4}{|c|}{$0.002237 \exp (-4337 / \mathrm{T})$} & $\mathrm{S} / \mathrm{m}$ \\
\hline
\end{tabular}

* $\mathrm{T}=\mathrm{T}_{\text {mat }}+273(\mathrm{~K})$
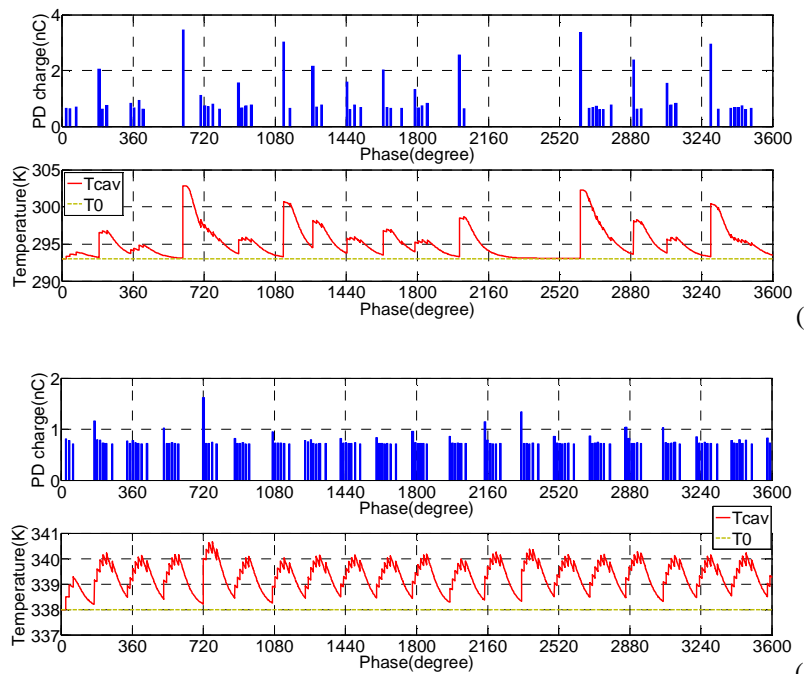

Fig. 6. Simulation of PD charge magnitude and temperature in the cavity for temperature (a) $20^{\circ} \mathrm{C}$ and (b) $65^{\circ} \mathrm{C}$

\section{CONCLUSIONS}

A finite element analysis model has been developed to describe PD activity within a spherical cavity in a dielectric material as a function of temperature. When the temperature of the material is increased, the electron generation rate increases, resulting in higher rates of PD repetition. However, the maximum surface conductivity increases with temperature because of faster charge movement along the cavity wall, consequently the effect of the charge decay rate becomes more significant at higher temperatures. The effect of temperature change in the cavity on the next PD occurrence is more significant at lower temperatures due to higher number of PDs occurring with larger charge magnitudes.

\section{REFERENCES}

[1] D. A. Seanor, "Electrical Properties of Polymers," Academic Press, Inc., 1982.

[2] R. Schifani, R. Candela, and P. Romano, "On PD mechanisms at high temperature in voids included in an epoxy resin," IEEE Transactions on Dielectrics and Electrical Insulation, vol. 8, pp. 589-597, 2001.

[3] H. A. Illias, G. Chen, and P. L. Lewin, "Modelling of surface charge decay in a spherical cavity within a solid dielectric material using Finite Element Analysis," International Symposium on High Voltage Engineering, 2009.

[4] L. Niemeyer, "A generalized approach to partial discharge modeling," IEEE Transactions on Dielectrics and Electrical Insulation, vol. 2, pp. 510-528, 1995.

[5] F. Gutfleisch and L. Niemeyer, "Measurement and simulation of PD in epoxy voids," IEEE Transactions on Dielectrics and Electrical Insulation, vol. 2, pp. 729-743, 1995.

[6] G. C. Crichton, P. W. Karlsson, and A. Pedersen, "Partial discharges in ellipsoidal and spheroidal voids," IEEE Transactions on Electrical Insulation, vol. 24, pp. 335-342, 1989.

[7] M. D. L. d. Casale and R. Schifani, "Direct interaction between partial discharge and temperature on epoxies: phenomenological life models," $J$. Phys. D: Appl. Phys., vol. 35, pp. 33-39, 2002.

[8] B. M. Weedy, D. Chu, and A. E. Davies, "Electric stresses in an hvdc cable through joint," IEEE Transactions on Power Apparatus and Systems, vol. PAS-103, pp. 383-388, 1984. 